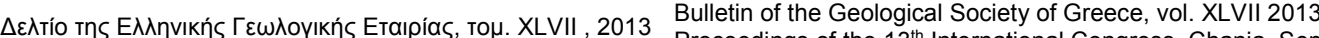
Proceedings of the $13^{\text {th }}$ International Congress, Chania, Sept.

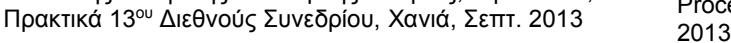

\title{
"GEO-CHARACTERIZATION" OF SELECTED AREAS IN CRETE, GREECE, TOWARDS REALISTIC ASSESSMENT OF SEISMIC DESIGN ACTIONS
}

\author{
Vafidis A. ${ }^{1}$, Steiakakis M. ${ }^{1}$, Agioutantis Z. ${ }^{1}$, Andronikidis N. ${ }^{1}$, Kritikakis G. ${ }^{1}$, \\ Economou N. ${ }^{1}$, Pandi K. ${ }^{1}$, Spanoudakis N. ${ }^{1}$, Savvaidis A. ${ }^{2}$, Margaris B. ${ }^{2}$, \\ Theodoulidis N. ${ }^{2}$, Lekidis V. ${ }^{2}$, Karakostas Ch. ${ }^{2}$, Mangriotis M.-D. ${ }^{2}$, Kalogeras \\ $\mathrm{II}^{3}$, Koutrakis S. ${ }^{3}$, Rozos D. ${ }^{4}$, Loupasakis C. ${ }^{4}$, Rondoyanni Th. ${ }^{4}$, Tsangaratos \\ P. ${ }^{4}$, Dikmen U. ${ }^{5}$, Papadopoulos N. ${ }^{6}$, Sarris A. ${ }^{6}$, Soupios P. ${ }^{7}$, Kokkinou E. ${ }^{7}$, \\ Papadopoulos I. ${ }^{7}$, Kouli M. ${ }^{7}$ and Vallianatos F. ${ }^{7}$ \\ ${ }^{*}$ Technical University of Crete, Department of Mineral Resources Engineering, \\ vafidis@mred.tuc.gr \\ ${ }^{2}$ Institute of Engineering Seismology and Earthquake Engineering (EPPO), Thessaloniki, Greece \\ ${ }^{3}$ Geodynamic Institute, National Observatory of Athens, Greece \\ ${ }^{4}$ Laboratory of Engineering Geology and Hydrogeology, Department of Geological Sciences, \\ School of Mining and Metallurgical Engineering, National Technical University of Athens, Greece \\ ${ }^{5}$ Department of Geophysics, Ankara University, Turkey \\ ${ }^{6}$ Laboratory of Geophysical-Remote Sensing \& Archaeoenvironment, Institute for Mediterranean \\ Studies, Foundation for Research \& Technology Hellas, Greece \\ ${ }^{7}$ Laboratory of Geophysics and Seismology, Department of Natural Resources and Environment, \\ Technological Educational Institute of Crete, Chania, Grete, Greece
}

\begin{abstract}
The geo-characterization of site conditions is crucial for the estimation of regional elastic spectra. The work to be done in the framework of the "GEOCHARACTERIZATION" THALIS-project, will combine geotechnical and geophysical methods and evaluate them to estimate critical geotechnical parameters. Although geotechnical tests in lab may provide more accurate estimates of geotechnical parameters, they require costly and time consuming drilling procedures. On the other hand geophysical methods are useful in providing estimates in situ of subsurface physical properties, which are not directly related to geotechnical parameters. Within "GEO-CHARACTERIZATION" THALIS-project a pilot survey for geotechnical characterization at selected sites of Hellenic Accelerometric Network in Crete will be conducted by employing geotechnical, geological and geophysical techniques. Subsequently, by correlating "geo-data" collected within this project, relations of certain mechanical parameters obtained in laboratory or/and in situ with geophysical parameters for typical geologic formations and soils will be established. The "GEO-CHARACTERIZATION" project, will focus on the influence of dynamic loads on geotechnical phenomena related to the static stress field variation, the estimation of site effects due to seismic motion and the proposal of regional elastic spectra for seismic provisions as well as their comparison with the corresponding elastic design spectra of Eurocode 8 (EC8). Key words: Natural Hazards, Earthquake Risk, Eurocode 8, Regional Elastic Spectra, Crete.
\end{abstract}

$\underline{\text { XLVII, No } 3-1439}$ 


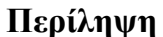

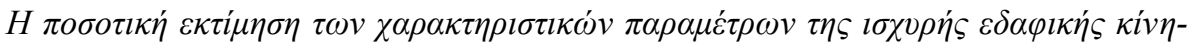

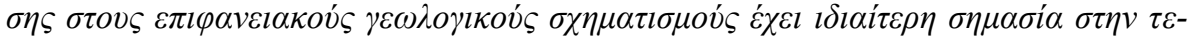

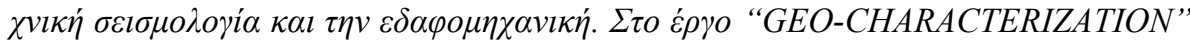

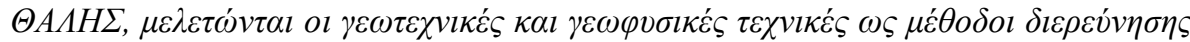

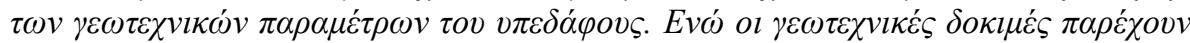

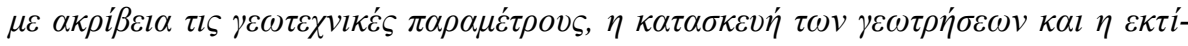

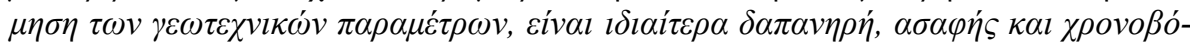

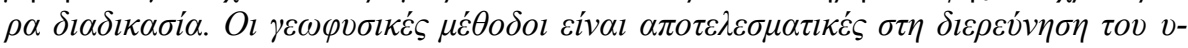

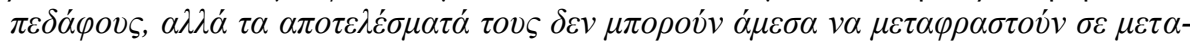

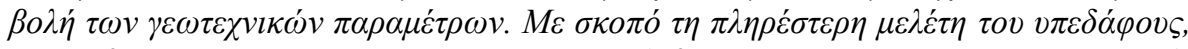

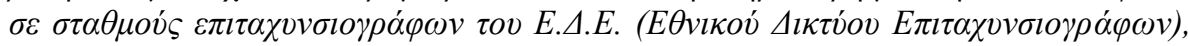

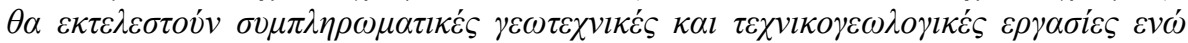

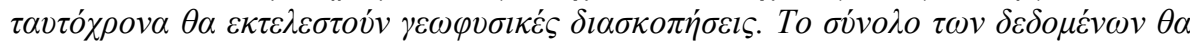

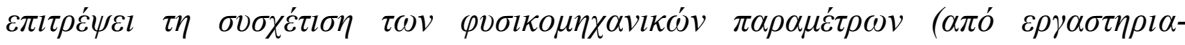

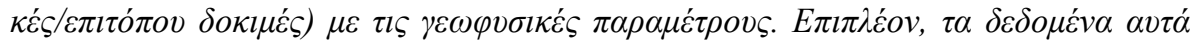

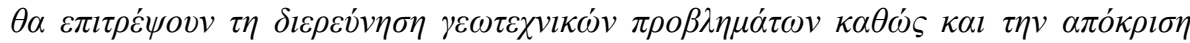

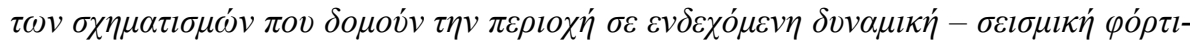

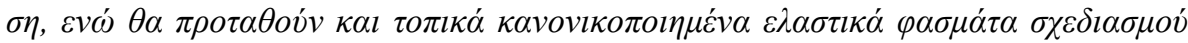

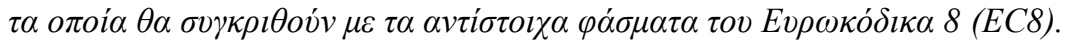

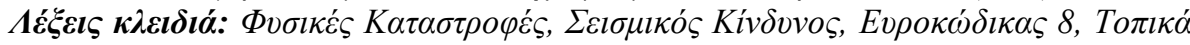

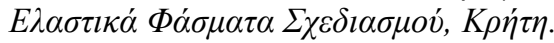

\section{Introduction}

The estimation of the strong motion parameters for the shallow geological formations is essential for engineering seismology and soil mechanics. There is a plethora of studies which verify the correlation between site conditions and earthquake damages (Borcherdt, 1970; Bouckovalas et al, 1996; Atakan et al., 1997; Raptakis et al., 2005; Marka et al., 2005; Improta et al., 2005; Tyagunov et al., 2006; Lombardo et al., 2006; Rayhani et al., 2008; Razaei et al., 2009).

Wills et al. (2000) utilized the weighted velocity $\mathrm{V}_{\mathrm{S}, 30}$ for the soil formations classification in California (USA), based on the U.B.C., while Kanli et al. (2006) classified soil formations based on the EC8 at Dinar, SW of Turkey. Carvalho et al. (2009) applied the seismic refraction method for both the characterization of soil formations (based on EC8) and the estimation of the Poisson ratio in the framework of a micro-zonation study at Western Portugal. Theodulidis et al. (2006) used stochastic methods for the calculation of synthetic accelerometer records for the 1978 Thessaloniki seismic event, based on geotechnical, geophysical and geological data.

Grasso and Maugeri (2009) performed seismic risk analysis in Catagnia (Italy) using seismicity (Barbano and Rigano, 2001), geological and geophysical studies (Cavallaro et al., 2006, Trovato et al., 2003, Beranzoli and Favali, 2005) as well as soil behavior studies of seismic loads (Grasso et al., 2005). Anagnostopoulos et al. (2008) created a GIS platform for the estimation of possible damages in Chania, Crete-Greece. This study involved spectral analysis of surface waves for the characterization of the site effects.

Pitilakis et al. (1992) utilized geophysical and lab measurements (e.g. triaxial compression tests on typical soil samples), in order to determine the Young's modulus. Raptakis et al. (1995) correlated the velocity $\mathrm{V}_{\mathrm{S}}$ with in situ geotechnical parameters (SPR) for representative soils in Greece. Cicinioglou et al. (2007) used empirical relations for the seismic risk analysis in Instanbul, taking into consideration both the strong ground motion of shallow formations and the degradation (i.e. liquefaction) of formations subjected to seismic loads. In order to achieve this they calculated the Liquefaction Potential Index (LPI) (Iwasaki et al., 1978). For the estimation of the bearing capacity they utilized assumptions proposed by Richards et al. (1993). Inci (2002) studied the

XLVII, No 3 - 1440 
influence of argillaceous soils water saturation on the maximum shear modulus $\left(\mathrm{G}_{\max }\right)$ and Poisson ratio (v). They utilized ultrasonics and compared their results with the empirical relations derived by Hardin and Black (1968).

Turesson (2007) compared the shear modulus derived by geophysical measurements (the seismic refraction method and the multi-channel surface wave analysis (MASW) method) with the corresponding modulus calculated by the empirical relation which was proposed by Hardin and Black (1968) and was modified by Higuchi et al. (1981). A lot of effort has been put also for the correlation of the seismic parameters of rocks with their mechanical behavior (Sjörgen et al., 1979, McCann et al., 1990, Isik et al., 2008). El-Naqa (1996) estimated the indices RMR, Q $\kappa \alpha 1$ RQD, from velocity of $\mathrm{P}$ and $\mathrm{S}$ waves, using empirical relations (Sjörgen et al., 1979). Finally, Tezcan et al. (2006) correlated P and S waves velocity with the specific weight and the bearing capacity of the subsurface.

The “GEO-CHARACTERIZATION" THALIS-project focuses on: a) the influence of dynamic loads on geotechnical phenomena related to the static stress field variation, b) the estimation of the site effects due to seismic motion and c) the proposal of regional elastic spectra for seismic provisions as well as their comparison with the corresponding Greek Seismic Code (GSC2000) and Eurocode 8 (EC8) elastic design spectra.

The specific study employs survey technologies based on geophysical and geotechnical methods as well as intensity and spectral characteristics of seismic motion. This study aims at the improvement of construction safety by determining representative earthquake spectral characteristics in Crete. More specifically, updating the elastic design spectra of the existing GSC2000 and Eurocode EC8, should lead to increased seismic safety through efficient and representative construction planning actions in southern Aegean area.

\section{Methodology}

The “GEO-CHARACTERIZATION” THALIS-project involves the following investigations in Crete:

- Selection of stations from the Hellenic Accelerometric Network (HAN) in Crete.

- Complementary geotechnical and engineering geology field work and lab tests.

- Geophysical survey.

- Correlation of physico-mechanical parameters with geophysical parameters.

- Regional elastic spectra for seismic provisions.

\subsection{Complementary Geotechnical Engineering Geology Field Work and Lab Tests}

This field work involves new geotechnical investigation and borehole drilling at the selected strong motion sites of HAN including engineering geological mapping and neotectonic study of the wider area, in situ tests (SPT, downhole etc) within the boreholes as well as high quality sampling at selected horizons not only from boreholes, but also from open pits and slopes. This field work complements existing geotechnical and engineering geological data in the literature and other available resources such as geotechnical companies and administrative authorities. Thus, the outcome of this investigation is detailed geological-geotechnical mapping of the area around selected HAN sites in Crete including tectonic and neotectonic data.

Laboratory tests on representative soil samples involve grain size analysis, Attenberg limits determination, moisture content, density, porosity, permeability tests, CUPP-triaxial compression tests. On the rock samples, lab tests provide estimates of moisture content, density and porosity, Young's (elastic) modulus (E) and Poisson ratio (v), (axial compression and ultrasonics tests). All

XLVII, No 3 - 1441 
the above mentioned tests follow the Technical Specifications E105-86 and ASTM. The mechanical parameters estimated by the lab tests will be subsequently correlated with the physical parameters deduced from the geophysical survey.

\subsection{Geophysical Survey}

After the geological/engineering investigation, a geophysical survey will be carried out. The geophysical survey consists of survey design, data acquisition and processing as well as combined interpretation for the geotechnical characterization of the soil formations. Survey design involves the selection of the proper geophysical techniques for imaging the subsurface and tests for the optimum survey parameters estimation. S-wave techniques using one (VSP) or more boreholes (cross-hole tomography) provide the most reliable $\mathrm{V}_{\mathrm{S}}$ estimates, but their cost is high. The geocharacterization using borehole samples and geophysical measurements in boreholes, is extended using surface geophysical methods, such as seismic refraction and multichannel analysis of surface waves including microtremor spectral analysis of surface waves. The seismic methods will provide: (a) Detailed two-dimensional velocity ( $\mathrm{P}$ and $\mathrm{S}$ ) models, (b) Attenuation models (Q factor), (c) Mechanical characteristics of the bedrock.

Electrical methods are non-destructive high resolution methods, which are widely used in complex problems of geotechnical engineering. The development of modern multi-channel geophysical instruments for the automated and rapid acquisition permits a realistic subsurface imaging. All the above, make electrical methods and especially electrical tomography the most emerging methods in geotechnical geophysics. The application of electrical/electromagnetic methods including Vertical electrical sounding - (VES) and Transient electromagnetics (TEM) will provide: (a) Detailed two-dimensional electrical resistivity model, (b) Morphological characteristics of the bedrock, (c) Images of the fractured and water saturated zones.

\subsection{Correlation of Physico-mechanical Properties with Geophysical Parameters}

Although geophysical methods image the subsurface very effectively, most of the estimated physical parameters (such as electrical resistivity) cannot be explicitly related to geotechnical parameters because of the lack of relevant theoretical equations. Cross plots appropriate for certain lithologies are employed for the geotechnical characterization of the subsurface.

Existing empirical relations concerning soil formations will be initially, tested and modified for the soils under investigation. These empirical equations relate seismic velocity $\left(\mathrm{V}_{\mathrm{P}}\right.$ and $\left.\mathrm{V}_{\mathrm{S}}\right)$ and/or electrical resistivity with geotechnical parameters such as mechanical properties, porosity, moisture content, sand and clay percentage. Empirical equations for specific lithotypes are useful for the low cost and safe geo-characterization which employs high quality geophysical images as well as borehole and lab data. The “GEO-CHARACTERIZATION” THALIS-project will establish equations correlating mechanical and geophysical parameters deduced from geotechnical and geophysical investigations. Following the crossplots development and the assessment of the corresponding empirical equations, these equations will be employed for the geotechnical interpretation of geophysical sections.

Classification methods are an emerging technology concerning interpretation of seismic and electrical data. Still, the ads and pros of each classification method are not clearly specified. In general, one can employ automated or user defined classification methods. Automated classification methods are data dependent, while the latter classification methods require additional information (e.g. borehole data). Each geophysical method produces values (velocity, electrical resistivity etc) of soil properties, which define a multi dimensional vector. Every vector can be imaged on a scatter plot. Proximity of points on such a scatter plot corresponds to similar characteristics. Classification techniques control the organization of points in a multi dimensional scatter plot, searching for populations of points with similar measurements combination. These techniques differ from each other in the way they organize each population.

XLVII, No $3-1442$ 
In this project algorithms of K-means and neural networks (SOM-Self Organizing Maps) will classify geophysical and geotechnical data. The above mentioned methods of classification will be assessed, regarding their use for the geotechnical interpretation of geophysical sections.

\subsection{Regional Elastic Spectra}

Site effects may drastically increase seismic hazard level and their assessment becomes a major concern in seismic risk mitigation. The most reliable methods for site effect estimation follow either an experimental or a theoretical approach: (i) The former approach, compares the spectral contents of the earthquake recordings obtained at the site of interest with a corresponding obtained at a nearby rock station called as reference site and (ii) The latter approach provides ground motion prediction based on a geophysical model of the site.

The European and American seismic codes regulation (EC8 and National Earthquake Hazards Reduction Program - NEHRP) employs a simple site classification based on time-averaged velocity of the first $30 \mathrm{~m}, \mathrm{~V}_{\mathrm{S}, 30}$. The simplicity of this site classification and the relatively low cost of the background site survey made the $\mathrm{V}_{\mathrm{S}, 30}$-based approach very popular, in particular because there is no alternative method which combines cost, simplicity, and physical relevance to the underlying phenomena. For seismic action estimation according to EC8 one has to characterize site conditions and suitably estimate soil amplification and corresponding peak ground motion for the site. Seismic provisions usually offer average design values covering nationwide needs. Variation in seismotectonic environment may significantly affect spectral content of ground motion resulting in turn to elastic design spectra that differ from corresponding seismic provisions' values. Thus, it becomes mandatory to investigate and test seismic code design spectral values over regions exhibiting a specific seismotectonic environment by employing either actual regional seismic recordings or/and new results from improved geophysical/geotechnical approaches for site characterization.

The "GEO-CHARACTERIZATION" THALIS-project will conduct a theoretical and experimental evaluation of the site effects in order to categorize selected HAN stations on Crete according to Eurocode 8. More specifically, using recorded ground motion data from intermediate depth events in Crete and surrounding area, the corresponding elastic response spectrum will be calculated for selected sites. These values are compared with those defined for the corresponding EC8 design spectrum for the seismic zone comprising the island of Crete.

The final outcome of this work is the proposal of regional normalized elastic spectra for seismic design of structures and urban development planning. By comparing them with Eurocode provisions we will pinpoint differences that could be taken into account for improving seismic design actions in southern Aegean area.

This project involves the creation of a database containing geophysical and geotechnical data as well as seismic event records from HAN sites. Intermediate depth seismic events will be highlighted due to their relation with the African plate and extended damages on Crete. If there is a lack of relevant seismic events, a simulation for similar seismotectonic environments will be implemented utilizing seismotectonic models of the south Aegean arc. Finally, this database will include additional information (pictures, construction sections, seismic vulnerability reports) of the buildings hosting the accelerometers of HAN.

\section{Expected Results}

The specific study will provide: (a) survey technologies based on geophysical and geotechnical methods, (b) new or upgraded equations relating physico-mechanical properties and the parameters estimated by geophysical investigation, (c) assessment of neural networks in the classification of geophysical and geotechnical parameters, d) theoretical and experimental estimation of the site effects at HAN sites on Crete, (e) database, (f) normalized elastic spectra for construction planning and comparison with the GSC2000 and EC8 and (g) webpage.

XLVII, No $3-1443$ 
Summarizing, end-users may obtain data and technology for rapid and cost-effective highresolution non-invasive evaluation of seismic risk.

Main target groups are public administration, the construction companies at national level and all construction engineers in Crete. Their benefits are in:

- Construction planning with improved seismic safety and

- soil characterization with reduced cost, as there is also a reduction of the number of boreholes needed

The "GEO-CHARACTERIZATION" THALIS-project leads to the establishment of a multidisciplinary research group, whose main interest is the geo-characterization of selected sites on Crete using integrated geophysical and geotechnical methods. Similar studies, for the derivation of normalized elastic spectra are necessary at other earthquake prone regions in Greece. The members of this research group plan to continue their collaboration on the specific topic by carrying out such studies.

The effective dissemination of results will be achieved through the following levels:

- Presentations at conferences: The project includes a commitment to disseminate via presentations at conferences by academic partners.

- Scientific publications: The university participants are free to publish their results in open literature.

- Education: scientific knowledge will be disseminated within the involved Universities through research, education and training.

- Website: A website will be created, which will include the new technology created, application examples of the proposed methodology and restricted access of the end-users to the database of the project.

- Technological: Improvement of the services that the university and research institute laboratories can offer to the public administration and to private organizations operating in the construction and services sectors. The latter organizations can efficiently use the results in new constructions and re-evaluation of seismic safety of existing structures.

- Administration: dissemination at national and regional level of knowledge on safe and effective methods for assessment of seismic risk. This might have an important impact on new local and national regulations for seismic safety and urban land management.

\section{Acknowledgements}

This research has been financed by Greek national funds through the Operational Program "Education and Lifelong Learning" of the National Strategic Reference Framework (NSRF) Research Funding Program: THALES. Investing in knowledge society through the European Social Fund.

\section{References}

Anagnostopoulos S., Providakis C., Salvaneschi P., Athanasopoulos G. and Bonacina G. 2008. SEISMOCARE: An efficient GIS tool for scenario-type investigations of seismic risk of existing cities, Soil Dynamics and Earthquake Engineering, Vol. 28, p. 73 - 84.

Atakan K., Brandsdottir B., Halldorsson P. and Fridleifsson G.O. 1997. Site response as a function of near-surface geology in the South Iceland seismic zone, Natural Hazards, Vol. 15 (2-3), $139-164$. 
Barbano M.S. and Rigano R. 2001. Earthquake sources and seismic hazard in south-eastern Sicily, Annali di Geofisica, Vol. 44 (4), 723 - 738.

Beranzoli L. and Favali P. 2005. SN-1 - the first Italian seafloor observatory for seismic monitoring, in: Maugeri, M., (editor). Seismic prevention of damage: a case study in a Mediterranean city, Southampton, WIT Press, 367 - 376.

Borcherdt R D. 1970. Effects of local geology on ground motion near San Francisco Bay, Bulletin of Seismological Society of America, Vol. 60, 29 - 61.

Bouckovalas G., Anagnostopoulos A., Kapenis A. and Karantoni T. 1996. Analysis of soil effects and distribution of damage from the Pyrgos 1993 (Greece) earthquake, Geotech. Geolog. Eng. (Historical Archive), Vol. 14 (2), $111-128$.

Carvalho J., Torres L., Castro R., Dias R. and Mendes-Victor L. 2009. Seismic velocities and geotechnical data applied to the soil microzoning of western Algarve, Portugal, Journal of Applied Geophysics, Vol. 68, 249 - 258.

Cavallaro A., Grasso S. and Maugeri M. 2006. Clay soil characterization by the new seismic dilatometer marchetti test (SDMT), Proceedings of the second international conference on the flat dilatometer, Washington; April 2 - 5, 2006.

Cinicioglu S.F., Bozbey I., Oztoprak S. and Kelesoglu M.K. 2007. An integrated earthquake damage assessment methodology and its application for two districts in Istanbul, Turkey, Engineering Geology, Vol. 94, 145 - 165.

El-Naqa A. 1996. Assessment of geomechanical characterization of a rock mass seismic geophysical technique, Geotechnical and Geological Engineering, Vol. 14, 291 - 305.

Grasso S., Laurenzano G., Maugeri M. and Priolo E. 2005. Seismic response in Catania by different methodologies, in: Maugeri, M., (editor). Seismic prevention of damage: a case study in a Mediterranean city. Southampton: WIT Press, $63-79$.

Grasso S. and Maugeri M. 2009. The seismic microzonation of the city of Catania (Italy) for the maximum expected scenario earthquake of January 11, 1693, Soil Dynamics and Earthquake Engineering, Vol. 29, 953 - 962.

Hardin B.O. and Black W.L. 1968. Vibration modulus of normally consolidated clay, Journal of the Soil Mechanic and Foundations Division, ASCE, Vol. 94, 353 - 368.

Higuchi Y., Umehara Y. and Ohneda H. 1981. Evaluation of dynamic properties of the sand deposits under deep sea bed, Proceedings of the 36th Annual Convention of the Japanese Society of Civil Engineering, Vol. 3, 50 - 51.

Improta L., Di Giulio G., and Rovelli A. 2005. Variations of local seismic response in Benevento (Southern Italy) using earthquakes and ambient noise recordings, Seismology, Vol. 9 (2), $191-210$.

Inci G. 2002. Small-strain elastic response of compacted clayey soils during drying - an empirical approach, Proceedings of SAGEEP, pp. 15.

Isik S. N., Doyuran V. and Ulusay R. 2008. Assessment of deformation modulus of weak rock masses from pressuremeter tests and seismic surveys, Bull. Eng. Geol. Environ., Vol. 67, $293-304$.

Iwasaki T., Tatsuoka F. and Takagi Y. 1978. Shear Moduli of Sands Under Cyclic Torsional Shear Loading. Soils and Foundations, Japanese Society of Soil Mechanics and Foundation Engineering, Vol. 18, (1), $39-56$.

Kanli A.I., Tildy P., Pronay Z., Pinar A. and Hermann L. 2006. Vs,30 mapping and soil classification for seismic site effect evaluation in Dinar region, SW Turkey, Geophysical Journal International, Vol. 165, 223 - 235.

Lombardo G., Langer H., Gresta S., Rigano R., Monaco C. and Deguidi G. 2006. On the importance of geolithological features for the estimate of the site response: the case of Catania Metropolitan area (Italy), Natural Hazards, Vol. 38, 339 - 354

Marka K., Chavez-Garcia F.J., Raptakis D.G. and Pitilakis K.D. 2005. Parametric analysis of the seismic response of a $2 \mathrm{D}$ sedimentary valley: implications for code implementations of complex site effects, Soil Dyn. Earthqu. Eng., Vol. 25 (4), 303 - 315. 
McCann D.M. Culshaw M.G. and Northmore K. 1990. Rock mass assessments from seismic measurements, in Field Testing in Engineering Geology, Bell, F.G., Culshaw, M.G., Cripps, J.C. and Coeffy, J.R. (eds), Engineering Special Publication No. 6, Geological Society, London, 257 - 266.

Pitilakis D.K., Anastassiadis A. and Raptakis D. 1992. Field and laboratory determination of dynamic properties of natural soil deposits, Earthquake Engineering, Tenth World Conference, Balkema, Rotterdam, 1275 - 1280.

Raptakis G.D., Manakou V.M., Chavez-Garcia J.F., Makra A.K. and Pitilakis D.K. 2005. 3D configuration of Mygdonian basin and preliminary estimate of site response, Soil Dyn. Earthqu. Eng., Vol. 25, $871-887$.

Raptakis G.D., Anastassiadis J.A., Pitilakis D.K. and Lontzetidis S.K. 1995. Shear wave velocities and damping of Greek natural soils, $10^{\text {th }}$ European Conference on Earthquake Engineering, Balkema, Rotterdam, 477 - 1280.

Rayhani M.H.T., El Naggar M.H. and Tabatabi S.H. 2008. Nonlinear analysis of local site effects on seismic ground response in the Bam earthquake, Geotech. Geolog. Eng., Vol. 21 (1), 91 -100 .

Rezaei K., Guest B., Friedrich A., Fayazi F., Nakhaei M., Aghda F. and Beitollahi A. 2009. Soil and sediment quality and composition as factors in the distribution of damage at the December 26, 2003, Bam area earthquake in SE Iran (Ms=6.6), Journal of Soils Sediments, Vol. $9,23-32$.

Richards R., Elms D.G., Budhu M. 1993. Seismic bearing capacity and settlements of foundations, Journal of Geotechnical Engineering, Vol. 119 (4), 662 - 674.

Sjörgen B., Ofsthus A., and Sandberg J. 1979. Seismic classification of rock mass quality, Geophysical Prospecting, Vol. 27, $409-442$.

Tezcan S.S., Keceli A. and Ozdemir Z., 2006. Allowable bearing capacity of shallow foundations based on shear wave velocity, Geotechnical and Geological Engineering, Vol. 2403 - 218.

Theodulidis N., Roumelioti Z., Panou A., Savaidis A., Kiratzi A., Grigoriadis V., Dimitriu P. and Chatzigogos Th. 2006. Retrospective Prediction of Macroseismic Intensities Using Strong Ground Motion Simulation: The Case of the 1978 Thessaloniki (Greece) Earthquake (M6.5), Bulletin of Earthquake Engineering, Vol. 4, 101 - 130.

Trovato C., Vinciguerra S. and Imme G., 2003, Laboratory measurements of seismic velocities on rocks from Etna region (Italy), European Geophysical Society, Nice 2003, Vol. 1, 78 - 80.

Turesson A. 2007. A comparison of methods for the analysis of compressional, shear and surface wave seismic data and determination of the shear modulus, Journal of Applied Geophysics, Vol. 61, 83-91.

Tyagunov S., Hollnack D. and Wenzel F. 2006. Engineering-seismological analysis of site effects in the area of Cologne, Natural Hazards, Vol. 38, 199 - 214.

Wills J.C., Petersen M., Bryant W.A., Reichle M., Saucedo G.J., Tan S., Taylor G. and Treiman J. 2000. A Site Condition Map for California Based on Geology and Shear Wave Velocity, Bull. Seism. Soc. Am., Vol. 90 (6B), 187 - 208. 